\title{
Implementation Technology Augmented Reality Markerless in Historical of Muria Kudus University Android Based
}

\author{
Tajul Alwi ${ }^{1}$, Tri Listyorini ${ }^{2}$, Ratih Nindyasari ${ }^{3}$ \\ \{201451008@std.umk.ac.id ${ }^{1}$, trilistyorini@umk.ac.id ${ }^{2}$, ratihnindyasari@umk.ac.id $\left.^{3}\right\}$ \\ Department of Informatics Engineering, Gondang Manis POBOX 53 Bae Kudus, Indonesia ${ }^{123}$
}

\begin{abstract}
As in Universitas Muria Kudus (UMK) there is a 3D miniature available inside the Rectorate building which needs to be developed. This research aims to utilize technology by developing applications that can capture the historical forms of the UMK building. Recital, sophisticated, and attractive storage space. One of the technologies that is popular among the public is augmented reality technology. The research method that is Multimedia Development Life Cycle method which is until the distribution phase of the system. This application uses Kudan SDK library which capable of displaying 3D objects dimension of UMK buildings into a real environment using android smartphone. The result of this research is the application of android by using Marker less along with information related to UMK buildings, the Marker less serves as a substitute common marker to display object of building of UMK complete with a text and a description of the building.
\end{abstract}

Keywords: kudan SDK, augmented reality, marker less, MDLC.

\section{Introduction}

Information and communication technologies are evolving so quickly affects the range of existing media. It encourages people to get creative in managing science so that it is able to change the mindset of man to be able to think effectively and efficiently in order not to be left behind in the development of the world information and communication technology. In the development of information and communication technology currently involves the field of multimedia because it effectively to convey information. An organization or educational institution currently assume that the promotion is an important part of the marketing, because the institution was hoping with the promotions implemented can effectively compete with other institutions produce graduates or provide similar services. With the view of such promotional activities continuously and directional would be able to achieve maximum results.

This is certainly going to make an impact is good also in the promotion of an institution. University of Muria Kudus (UMK) is an institution of higher education are under the obligation to be able to produce competent scholars and professionals. As media campaigns, leveraging UMK role of technology such as web UMK via the internet. As for the capture or as an archive institution, UMK has miniature 3D image data and building scale by leveraging UMK. This miniature ornaments in the lobby moved so that visitors know publicly building

ICCSET 2018, October 25-26, Kudus, Indonesia

Copyright (C) 2018 EAI

DOI 10.4108/eai.24-10-2018.2280534 
UMK lecture. But the 3D miniature had some drawbacks, i.e. not practical in terms of size, because it requires a large space, can only be seen by people visiting the led, and in terms of the utilization of the technology looks less follow developments technology. Therefore, needed a technology that can perpetuate the historical forms which include building and profile Rector UMK in a medium that does not require a large space saving. More practically, sophisticated, and attractive.

One of the technologies in the field of multimedia is developing at the moment is Augmented Reality or better known as the reality of the increase in the language of Indonesia. Augmented Reality is a technology that combines the two dimensional and virtual objects or three dimensions into a real environment and then projecting the virtual objects in real time. Could be interpreted also that Augmented Reality that is abbreviated with the AR is the embodiment of the objects in the virtual world into the real world in either two dimensional or three dimensional [1]. Utilization of AR in identifying Historical UMK is extremely efficient in terms of storage space and certainly has some other advantages. By utilizing this AR, we just need a smartphone and android-based applications so that when a picture of the building on detection by camera smartphone application installed Historical UMK can display 3D images of buildings and the profile of the Rector of the UMK thoroughly or in detail. So in addition to the more practical in terms of media or space saving, technology is becoming more public interest will be building forms and profile Rector displayed similar to his original along with more complete information. Based on the above background, the researchers moved to develop an application of Augmented Reality (AR) Marker less as media introduction of the historical of the Universitas Muria Kudus.

\section{Related Research}

Application of Augmented Reality on Android applications as an introduction to Building University of Muria. This research focuses more on the location of a University building. The location and the building of the University was selected by the consideration that a University is composed of a diverse faculty in it, while the distinction of building one with more differentiated use only letter alphabet and as far as the author's observations haven't seen an easy and complete information about the building. Application architecture will be designed based Augmented reality [2].

$3 \mathrm{D}$ hologram introduction animals use holograms in the archipelago to introduce animals that existed in Indonesia is a way to provide an interactive and information more easily understood by the recipient of such information. It is expected also to be able to preserve the fauna in Indonesia [3]. Journal of product promotion media and 3D-based training. Discussion is to display detailed information of cigarette products from the pack and cigarette itself in the form of 3D Object. From the latest product types to the old products that are still produced where the 3D form will be displayed through a maker that will bring up 3 different 3D Objects. With the construction of this application is expected to help minimize expenses from the company and increase the attractiveness of the promotion of marketing products today [4].

"3D hologram as the media introduction of the ancient animal dinosaurs" Introduction to dinosaurs still uses the book as a medium to provide information. Any society that not many know what animal's dinosaurs as a whole can only see from the media books, television or another. Through multimedia technology approach using 3D hologram to provide information 
that is interesting and informative towards the community about animals that are now extinct dinosaurs and just leave fossils can still be seen [5].

\section{Methods}

\subsection{Multimedia Development Life Cycle (MDLC)}

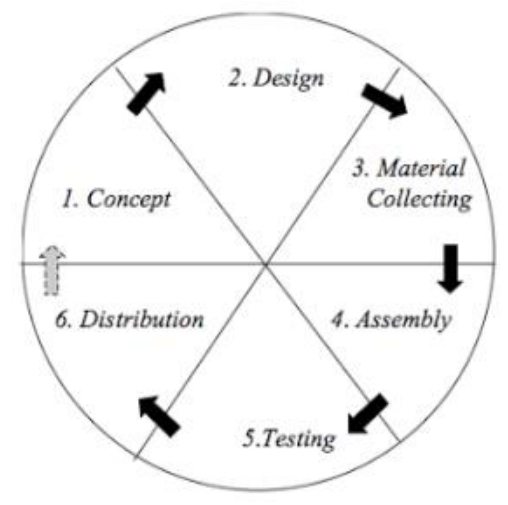

Fig. 1. Stage Metods of the MDLC.

a. Concept

Stage is where we find destinations, including audience, identify the type of application (interactive presentations, and others). The purpose of the application (information, entertainment, exercise, and others), and general specifications.

b. Design

At this stage the author does designing manufacture specs about architectural program, style, look, necessity of material or material creation of multimedia. The specifications made se and detailed as possible. In thine stage usually using storyboard dan description on the scene.

c. Material Collecting

At this stage of collecting material is the stage of the collection material in accordance with the needs of the development of multimedia.

d. Assembly

Stage is where all the multimedia material objects or created. The making of this application is based on storyboards and navigation structure that has been created on the stage of design. 


\section{e. Testing}

In the Testing done after the completion of the stage of manufacture and all the animations have been created then it will be done In stages of testing, this testing using alpha and beta. One of the things that should take precedence in the creation of animation was having to walk well with the environment of the user.

f. Distribution

At this stage, the application and all the information into a Library, at this stage is also the stage where the implementation and evaluation of a multimedia product in detail.

\subsection{Markerless Augmented Reality}

Marker less is an augmented reality method that does not require a marker as a reference for placing a 3 Dimensional object [6]. There are 3 pattern, face tracking, 3D object tracking, and motion tracking. The making of marker less itself is assisted by Kudan SDK which Kudan supports SLAM (Simultaneous Localization and Mapping) technology and provides database generation facility in Unity Editor. This augmented reality SDK uses a high performance Kudan CV engine that offers low memory footprint. The design of marker less pattern is shown in figure 2 The work process of marker less design is: Camera, ensuring that each frame is captured and forwarded efficiently to be tracked. Image Converter, a single pixel format converter that converts between camera formats to formats suitable for OpenGL rendering and for tracking. The tracker, contains a computer vision algorithm that detects and tracks real-world objects in video camera frames. Video Background Renderer to render camera images stored in a state object. Target Resource created using online management system. The application code, for application developers must initialize all the above components and perform three steps in the application code that is to ask the state object about the newly detected target or the latest state of this element. Then update application logic with new data input. The latter renders the graphical display embedded. 


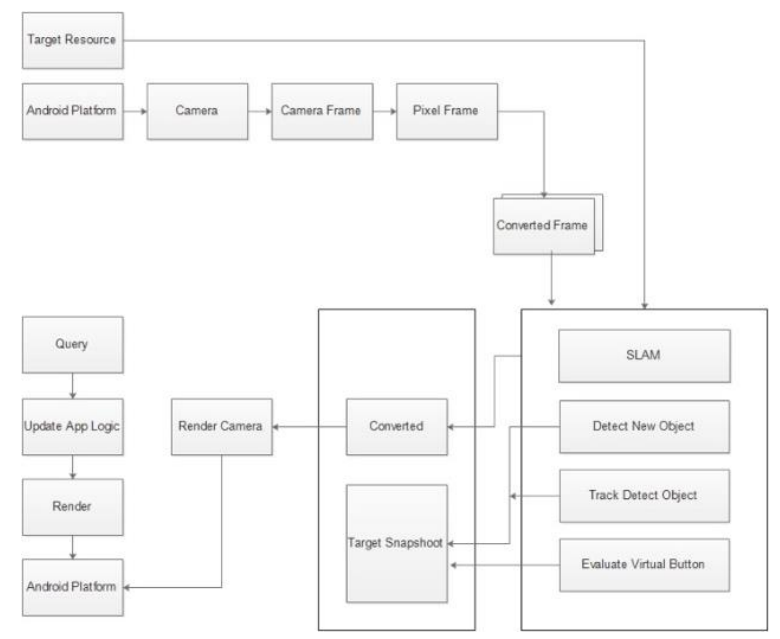

Fig. 2. Flow of Marker less Augmented Reality Application.

\section{Result}

Display the application after the install on the smartphone on each page 3D AR Marker less $3 \mathrm{D}$ application menu as a medium of information based on android historical is as follows.

\subsection{Splash Screen and Loading Page Views}

At the beginning of opening the application, it will open is the opening page before entering the main menu. Can be seen in Figure 2.

\subsection{Main Page Menu Display}

In the main menu view contains 4 sub menus, namely: Menu, Gallery, Profile and Info. Can be seen in Figure 3. 


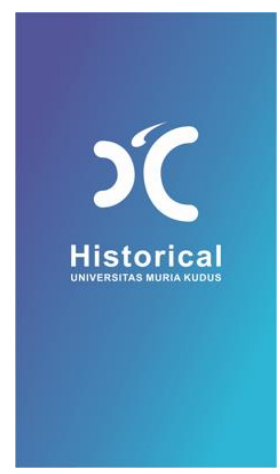

Fig. 2. Splash Screen and Loading Page views.

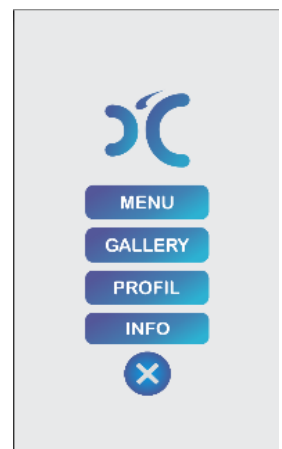

Fig. 3. Display Home Page.

\subsection{Menu AR Camera Display}

Menu AR 3D View of the main menu. Can be seen in Figure 4.

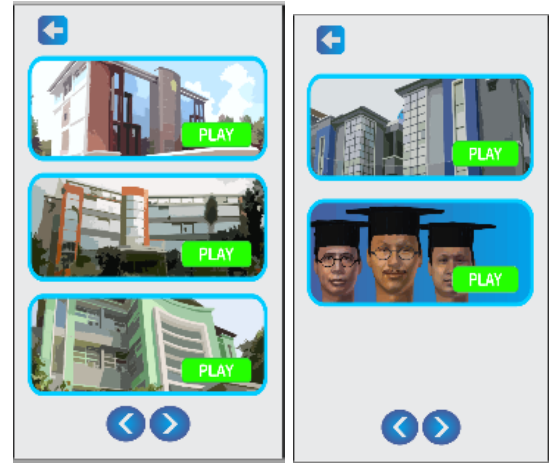

Fig. 4. Display Page Menu AR. 


\subsection{AR Camera Display Building of the Rectorate and Auditorium}

AR Camera display building of the Rectorate and Auditorium can be seen in Figure 5.
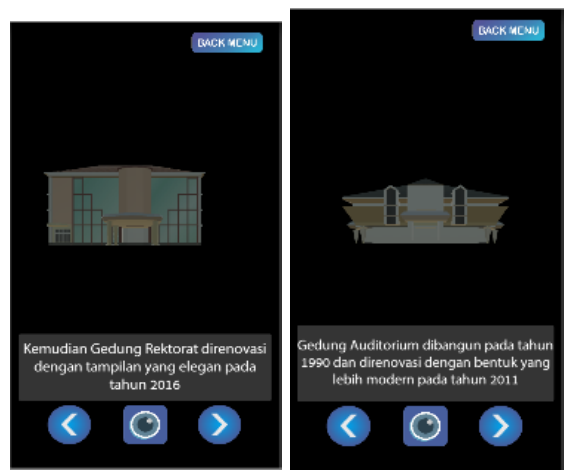

Fig. 5. AR Camera of Building Complex.

\subsection{AR Camera Display Building of the Building Orange (J) and Engineering Faculty}

AR camera display building of the building orange ( $\mathrm{J}$ ) and engineering faculty can be seen in Figure 6.
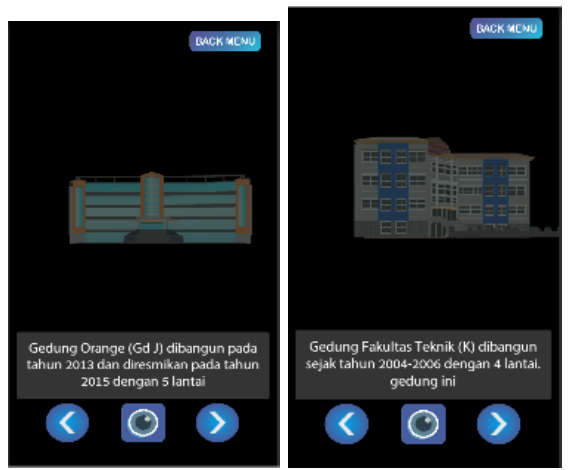

Fig. 6. AR Camera of Building Complex.

\subsection{AR Camera Display Building of the Economic Faculty and KIP Faculty}

AR Camera Display Building of the Economic Faculty and KIP Faculty can be seen in Figure 7. 

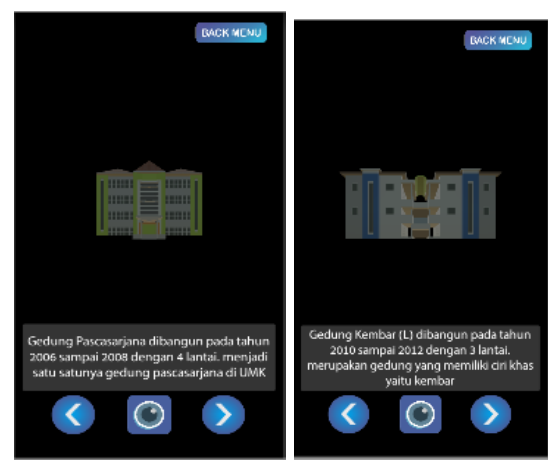

Fig. 7. AR Camera of Building Complex.

\subsection{AR Camera Display Building of the Rector Profile}

AR Camera Display Building of the Rector Profile can be seen in Figure 8.

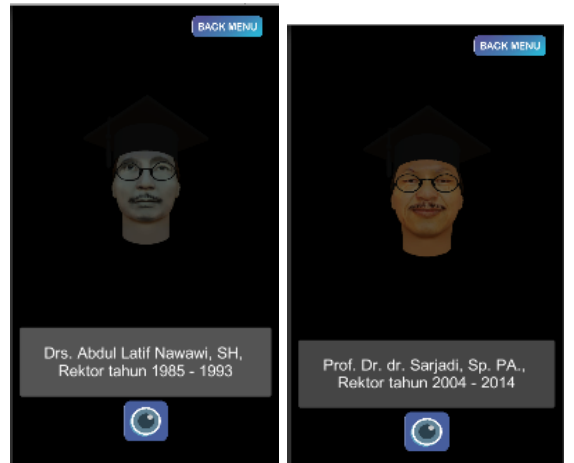

Fig. 8. AR Camera of Rector Profile.

\subsection{View of the building complex gallery}

View of the information gallery building complex gallery can be seen in Figure 9.
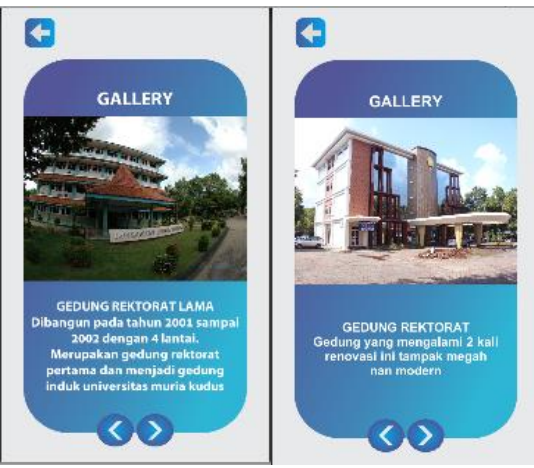

Fig. 9. Gallery of the Building Complex. 


\subsection{View of the rector profile}

View of the information gallery rector profile can be seen in Figure 10.

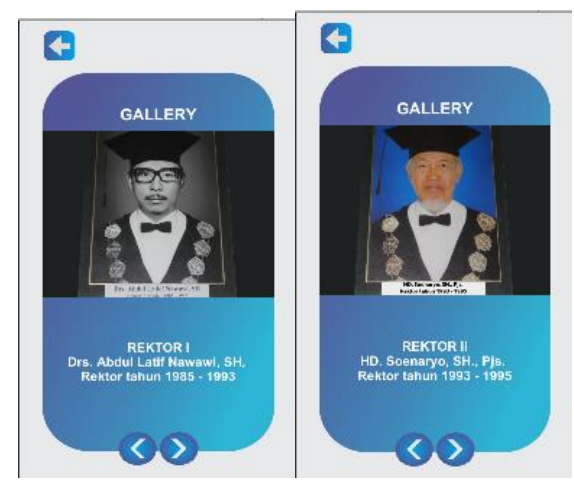

Fig. 10. Gallery of the Rector Profile.

From the results of research and discussion can be drawn conclusion as follows: In this research managed to build the application of Augmented Reality Marker less 3D as an information media of promotion based on interactive android Muria Kudus University Building using multimedia development method of MDLC (Multimedia Development Life Cycle) for introduction. And the second implementation of interaction using the application button further facilitate the user, all the buttons function according to function and the application runs smoothly on the android smartphone device and is expected to be useful for promotion in Muria Kudus University. In the application use must be considered the distance and focus of the camera. In order for the camera to detect better but the farther the camera focus will interfere with application performance. 3D objects created include the buildings and rector profile according to the constraints of the problem. Then accompanied by information about the Muria Kudus University. At the las this application is stored in the form of APK file (android package file), so that can be directly installed on the smartphone android [7].

\section{References}

[1] T. Listyorini, S. Rochman, and R. Meimaharani, "Three Dimensional Animation of How to Breed Rabbit," Telkomnika, vol. 16, no. 3, pp. 1309-1316, Jun. 2018.

[2] M. M. Imamul, "PENERAPAN AUGMENTED REALITY PADA APLIKASI ANDROID SEBAGAI PENGENALAN LOKASI GEDUNG UNIVERSITAS MURIA KUDUS,” Mar. 2014.

[3] A. Rizky, L. Tri, and L. Anastasya, "3D Hologram Pengenalan Hewan Nusantara," in SNATIF (Seminar Nasional Teknologi dan Informasi, Kudus, 2016, pp. 19-24.

[4] A. Santoso, T. Listyorini, and A. Susanto, "Aplikasi Android sebagai Media Alternatif Promosi Produk dan Training di PT DJARUM berbasis Augmented Reality," Simetris J. Tek. Mesin Elektro Dan Ilmu Komput., vol. 6, no. 2, p. 321, Nov. 2015.

[5] T. Listyorini, "3d-Catalog Mountain View Resident Berbasis Augmented Reality," in Saintiks, Bandung, 2014, p. I 25-30.

[6] A. C. Luther, Authoring Interactive Multimedia. San Fransisco: AP Professional, 1994.

[7] E. Kartikadarma, T. Listyorini, and R. Rahim, "An Android mobile RC4 simulation for education,” World Trans. Eng. Technol. Educ., vol. 16, no. 1, pp. 75-79, Apr. 2018. 